\title{
Development of membrane by using iron-containing synthetic materials for arsenic removal from water
}

\author{
L.R. Velázquez ${ }^{1}$, R.V. Moreno ${ }^{1}$, R.R. Mendoza ${ }^{1}$, C. Velázquez ${ }^{1}$ \& S.E. Garrido Hoyos ${ }^{2}$ \\ ${ }^{1}$ Facultad de Química, Universidad Autónoma de Querétaro, Santiago de Querétaro, Qro, Mexico \\ ${ }^{2}$ Subcoordinacción de Posgrado, Instituto Mexicano de Tecnología del Agua, Jiutepec, Mor., Mexico
}

\begin{abstract}
The presence of arsenic in the environment has been one of the main causes of contamination in surface and groundwater. Arsenic can be found in four oxidation states, such as trivalent arsenic (As(III)), pentavalent arsenic $(\mathrm{As}(\mathrm{V}))$, arsine $(\mathrm{As}(-\mathrm{III}))$ and elemental arsenic $\left(\mathrm{As}^{0}\right)$. It is mainly found as $\mathrm{As}(\mathrm{III})$ and $\mathrm{As}(\mathrm{V})$ in groundwater. In the present work, MDP's membranes were developed by an adsorbent material and two additives. The material was synthesized and characterized, obtaining a surface area of $55.005 \mathrm{~m}^{2} \mathrm{~g}^{-1}$ and a pore diameter of $34.11 \AA$, the material has a crystalline structure and tends to change its chemical composition from $281.14^{\circ} \mathrm{C}$. A $2^{3}$ factorial design was performed for to obtain the optimal conditions for the preparation of the membranes for the factors of adsorbent material goethite $(\mathrm{FeOOH})$, binder $\left(\mathrm{Al}_{2} \mathrm{O}_{3}\right)$ and lubricant $\left(\mathrm{C}_{18} \mathrm{H}_{36} \mathrm{O}_{2}\right)$. The membranes were pressed to 1.5 tons and sintered at $600^{\circ} \mathrm{C}$, converting the goethite material $(\mathrm{FeOOH})$ to hematite $\left(\mathrm{Fe}_{2} \mathrm{O}_{3}\right)$. The membrane was analyzed by physisorption of nitrogen and was obtained a surface area of $39.4249 \mathrm{~m}^{2} \mathrm{~g}^{-1}$ and a pore diameter of $83.01 \AA$. Finally the adsorption kinetics was performed for five membranes with the same characteristics of the MDP6 membrane. According to the kinetics, it was observed that the MDP2 membrane showed an elimination of $41 \%$ of arsenic $\mathrm{As}(\mathrm{V})$ at an initial concentration of $0.49 \mathrm{mg} \mathrm{L}^{-1}$.
\end{abstract}

\section{INTRODUCTION}

Arsenic in groundwater is due to natural activities such as the dissolution of minerals, geogenic activities (Tuesca et al., 2015). In groundwater is common to find arsenic as arsenate $(\mathrm{As}(\mathrm{V}))$ and arsenite (As(III)) (Sklari et al., 2015). In Mexico, several cases of groundwater contamination have been reported in the states of Durango, Coahuila, Hidalgo, Sonora and Querétaro. The consumption of water contaminated with arsenic can produce skin lesions with a hyper-pigmentation of the chest, neck, and trunk, with concomitant or later appearance of hyperkeratosis (Karagas et al., 2015). Consequently, Mexican Standard NOM-127-22A1-1994 set a limit of $0.025 \mathrm{mg} \mathrm{L}^{-1}$ of arsenic in drinking water. Finally, the use of porous membranes has been proposals as technology for the removal of contaminants in water. The aim of this work is the development of porous membranes by synthetic materials with iron oxyhydroxides for the removal of arsenic in water.

\section{EXPERIMENTAL SECTION}

\subsection{Preparation and characterization of adsorbent media}

The goethite was synthesized for the preparation of porous membranes following the methods by
Table 1. Experimental design.

\begin{tabular}{lll}
\hline & \multicolumn{2}{l}{ Intervals } \\
\cline { 2 - 3 } Factors & 1 & -1 \\
\hline Binder $(\mathrm{g})$ & 0.45 & 0.375 \\
Lubricant $(\mathrm{g})$ & 0.075 & 0.025 \\
Synthetic goethite $(\mathrm{g})$ & 2.1 & 1.975 \\
\hline
\end{tabular}

Garrido \& Romero (2015). The synthesized material was characterized for the phase identification by X-ray diffraction (XRD) Diffractometer D8 Advance Bruker radiation $\mathrm{Cu} K \alpha(\lambda=0.15406)$ range between $10-80^{\circ}$ to $2 \theta$. The textural properties (surface area, pore volume and size distribution) of the synthesized goethite were analyzed by Autosorb IQ2. The thermal stability of the synthetic goethite was also studied for TA instruments model Q500 temperature ranges from $10-1000^{\circ} \mathrm{C}$ and temperature ramp $5^{\circ} \mathrm{C} \mathrm{min}^{-1}$.

\subsection{Development membranes MDP's}

The development of eight membranes was carried out following the proposed methodology by Pérez et al. (2004). The experiments were carried out using a $2^{3}$ factorial design Statgraphics Centurion XV (Table 1).

Subsequently the material mixture was compacted in a hydraulic press at 1.5 ton and sintered at $600^{\circ} \mathrm{C}$ for three hours. The kinetics was performed in a 
continuous process for $8 \mathrm{~h}$. The As(V) concentrations were prepared with sodium arsenate heptahydrate $\left(\mathrm{Na}_{2} \mathrm{HasO}_{4} 7 \mathrm{H}_{2} \mathrm{O}, 98 \%\right.$ purity, Sigma-Aldrich).

Samples were taken at time intervals of $30 \mathrm{~min}$. The sample was filtered using a $0.45 \mu \mathrm{m}$ membrane. Arsenic was determined using the Wagtech photometer method.

\section{RESULTS AND DISCUSSION}

\subsection{Characterization of synthetic goethite $\mathrm{FeOOH}$}

According to the results of XRD the PDF database used was 29-0713. Spectra of synthetic goethite shows the characteristic reflections of goethite in positions $21.223,33.242,36.650$ and $53.2382 \theta$. The structure corresponds to a type of orthorhombic family and its crystal structure can be indexed between the crystallographic plans $110,130,111,221$. The results were compared with those reported by Jaiswal et al. (2013). Nitrogen adsorption, showed a type IV isotherm which corresponds to mesoporous solid and a type IV hysteresis curve. The characterization of synthetic goethite shows $55.005 \mathrm{~m}^{2} \mathrm{~g}^{-1}$ surface area, pore volume of $0.137 \mathrm{~cm}^{3} \mathrm{~g}^{-1}$ and pore diameter $(\mathrm{dV} / \mathrm{d}) 34.11 \AA$. Nevertheless Garrido \& Romero (2015) reported a pore diameter of $119.05 \AA$ is 3.49 times greater than the reported in this work. The thermogravimetric analysis indicates that the main mass loss occurs around $281.14^{\circ} \mathrm{C}$. The material presents a mass decrease which is attributed to the loss of iron hydroxides converting the material into hematite.

\subsection{Development membranes MDP's}

The particle size was $0.5 \mathrm{~mm}$. A statistically significant difference $(\mathrm{p}<0.005)$ was found for development membranes show lubricant. The optimal conditions for development membranes were: synthetic goethite of $2.1 \mathrm{~g}$, binder $0.450 \mathrm{~g}$ and lubricant $0.025 \mathrm{~g}$. The use of lubricant is essential to give resistance to membrane fragmentation. The membranes were characterized by XRD and physisorption of nitrogen. The selected membrane was analyzed from the experimental design and after a thermal sintering process of $600^{\circ} \mathrm{C}$ according to PDF 03-6664. The material is hematite since it is characterized by the main reflections in positions $24.138,33.153,35.612,49.480$ and 54.091 in $2 \theta$ with the crystallographic planes of $012,104,110$, 024 and 116 according to reported by Zhang et al. (2017). The surface area obtained in the membrane was $39.4249 \mathrm{~m}^{2} \mathrm{~g}^{-1}$.

\subsection{Kinetics sorption for membranes MDP's}

Figure 1 shows the five membranes selected to perform the adsorption kinetics MDP1, MDP2, MDP3, MDP4 and MDP5.

The values fitted to pseudo-second order equation, and the best results were for MDP2 membrane with kinetics constants: Adsorption capacity,

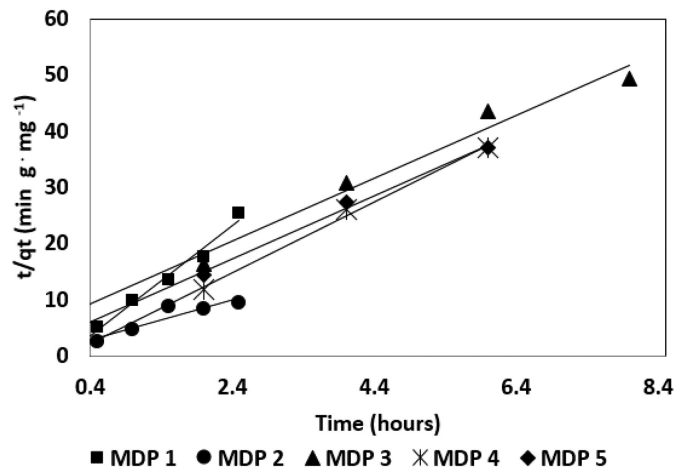

Figure 1. Kinetics sorption of As(V).

qe: $0.287 \mathrm{mg} \mathrm{g}^{-1}$;Adsorption rate kad: $3.67 \mathrm{mg} \mathrm{min}^{-1}$; and initial velocity rate, $\mathrm{h}: 0.303 \mathrm{mg} \mathrm{g}^{-1}$ with $\mathrm{R}^{2}$ : 0.8503 .

\section{CONCLUSIONS}

In this experiment the addition of lubricant was of great importance, without this additive the membranes were easily broken. However, it is recommended to use moderate amounts of lubricant, to obtain a better removal performance of membranes conforming by Hematite. The membrane MDP2 had an arsenic removal of $41 \%$ with an initial concentration of $0.49 \mathrm{mg} \mathrm{L}^{-1}$ of As(V).

\section{REFERENCES}

Garrido, S. \& Romero, L. 2015. Synthesis of minerals with iron oxide and hydroxide contents as a sorption medium to remove arsenic from water for human consumption. Int. J. Environ. Res. Public Health 13(1): 69.

Jaiswal, A., Banerjee, S., Mani, R. \& Chattopadhyaya, M.C. 2013. Synthesis, characterization and application of goethite mineral as an adsorbent. J. Environ. Chem. Eng. 1(3): 281-289.

Karagas, M.R., Gossai, A., Pierce, B. \& Ahsan, H. 2015. Drinking water arsenic contamination, skin lesions and malignancies: a systematic review of the global evidence. Curr. Environ. Health Rep. 2(1): 52-68.

Pérez, M.V., Castro, A.J. \& Balmori, R.H. 2004 Characterization and preparation of porous membranes with a natural Mexican zeolite. J. Phys. Condens. Matter 16(22): S2345.

Sklari, S., Pagana, A., Nalbandian, L. \& Zaspalis, V. 2015. Ceramic membrane materials and process for the removal of As (III)/As (V) ions from water. J. Water Process Eng. 5: $42-47$.

Tuesca, R., Ávila, H., Sisa, A. \& Pardo, D. 2015. Fuentes de abastecimiento de agua para consumo humano: análisis de tendencia de variables para consolidar mapas de riesgo. Barranquilla, Colombia: Universidad del Norte.

Zhang, Y., Dong, K., Liu, Z., Wang, H., Ma, S., Zhang, A. \& Li, Y. 2017. Sulfurized hematite for photo-Fenton catalysis. Pro. Nat. Sci-Mater. 27(4): 443-45. 